\title{
Rylene Dielectrophores for Capacitive Energy Storage
}

\author{
Andrey Borzenko1, Carine Edder ${ }^{1}$, Lev Mourokh ${ }^{1,2,3}$, Pavel Lazarev1 \\ ${ }^{1}$ Capacitor Sciences Inc., Menlo Park, USA \\ ${ }^{2}$ Department of Physics, Queens College of the City University of New York, Flushing, USA \\ ${ }^{3}$ The Graduate Center of CUNY, New York, NY, USA \\ Email: andrey.borzenko@capacitorsciences.com
}

How to cite this paper: Borzenko, A., Edder, C., Mourokh, L. and Lazarev, P. (2018) Rylene Dielectrophores for Capacitive Energy Storage. Materials Sciences and Applications, 9, 534-541. https://doi.org/10.4236/msa.2018.96038

Received: March 28, 2018

Accepted: May 28, 2018

Published: May 31, 2018

Copyright (c) 2018 by authors and Scientific Research Publishing Inc. This work is licensed under the Creative Commons Attribution International License (CC BY 4.0).

http://creativecommons.org/licenses/by/4.0/

\begin{abstract}
Main design principles of the potent rylene-based class of dielectrophores are established in the present article. The proposed class of dielectrophores comprises polarizable aromatic core, conjugated with aromatic subunits, and bears resistive groups on the periphery. The aromatic subunits might comprise donor and acceptor groups for the desired level of polarizability of the molecule. Appropriate positions for donor and acceptor groups are established by quantum chemistry modeling. The design principles are demonstrated on the molecular design of an efficient rylene-based dielectrophore.
\end{abstract}

\section{Keywords}

Dielectrophore, Polarization, Capacitor, Molecular Dielectrics, Molecular Design

\section{Introduction}

Rapidly growing demand of efficient energy storage motivates the development of inexpensive and safe energy-storing materials [1]. Humans have entered a new era when electricity is fully integrated into each aspect of modern life. Surrounded by electricity powered manufacturing, household gadgets, electric transportation, internet-based business and social communications, we still commonly experience energy disruptions significantly limiting the speed of development of the expected innovative future. Therefore, new efficient approaches to the energy storage are in high demand, and it is possible that efficient solutions can very quickly fill the empty niche. The multiplicity of proposed and coexisting technological solutions of energy storage demand is an evidence of the fact that basic principles based solution, the "wheel of energy storage" so to 
speak, is still being expected to arrive.

Currently produced volume of electricity-about 25,000 Terawatt hours per year-with reasonable requirement of 24 hours storage cycle demands about 10 Megatons of energy storage material. Assuming that $1 \mathrm{kWh}$ is stored in $1 \mathrm{~kg}$ of energy storage material, it can take more than 10 years to produce the required amount of material.

Design principles start with very basic assumption that there are no chemical transformations and moving parts in future energy storage devices. Electrons are moved in the device and electrons are moved out of the device-it is capacitor as it was designed in 1745 by the Prussian scientist Ewald Georg von Kleist and independently by the Dutch physicist Pieter van Musschenbroek [2].

Setting up the design rules of energy storage, we apply general principles of efficient capacitors at the molecular level. Dielectric species in high energy storage capacitor should be polarizable and, at the same time, should be resistive, keep low leakage current, and maintain the polarization energy without breakdown. These properties seem to contradict each other, as the polarization is caused by the motion of the charges, but this motion must be stopped at some certain points to prevent conduction and charge recombination at the electrodes. Hence, our molecular units should contain at least two parts, the inner being responsible for the polarization, and the peripheral one having required resistance, in other words, polarizable core in resistive envelope.

In this paper, we discuss a new class of molecules, dielectrophores, with polarizable core and resistive peripheral structure. Recently, [3] we have presented rylene-based dielectrophore structure that combines the required capacitors properties. This class of aromatic molecules is known to be highly polarizable [4]. The full spectrum of colors that is easily achieved with rylene-based molecules can be a great representation of the unique controlled polarizability of these species [4]. This exclusive feature has been recognized and applied in rylene-based dye industry for many years, however, it has no application in the energy storage. In addition to the polarizability, rylenes have convenient physical properties and good mechanical flexibility that provides an opportunity to create a particular form of a capacitor for each application [5].

\section{Rylene-Based Dielectrophores}

We can allocate three main components of the rylene-based dielectrophores, as shown in Figure 1. The main polarizable component is an aromatic core that can participate in $\pi-\pi$ stacking with other aromatic molecules. The core can be directly conjugated with other subunits, which can bring significant impact into the total polarizability of a molecule. It is noteworthy, that the total polarizability is also dependent upon the installation of appropriate functional groups on the core as well as subunits. Moreover, for these rylene-based structures to stay resistive for leakages, additional insulating subunits on the periphery are required. These groups may not only work as breakdown insulating subunits, but also 


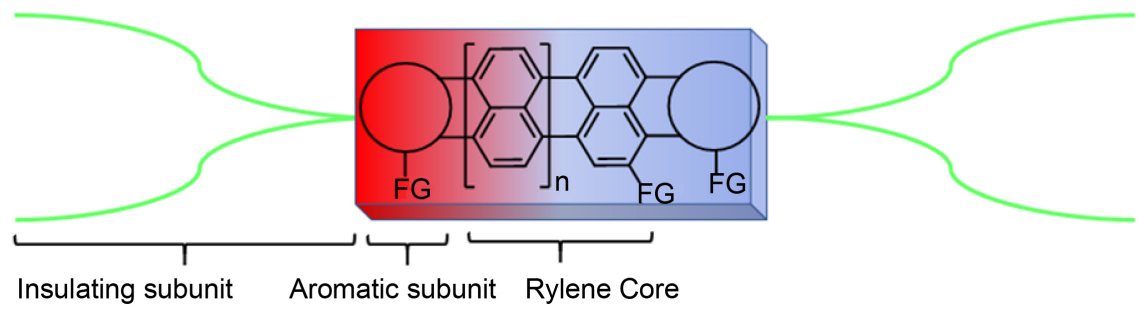

Figure 1. General rylene-based dielectrophore structure.

provide solubility to the molecular system and simplify the synthesis and processability.

Perylene-based species (Figure 1) are among the planar polycyclic molecular systems which form column-like supramolecular stacks (self-assemblies) by $\pi-\pi$ interactions, see Figure 2 [6]. Aliphatic alkyl or fluoroalkyl chains in such ordered structures of perylene-based dielectrophores are sufficient to form so-called "insulating envelope" for the useful resistivity of $>10^{16} \Omega \cdot \mathrm{cm}[7]$.

For the optimal formation of the described self-assemblies shown in Figure 2, the aromatic core needs to have at least a two-fold core symmetry. Therefore, perylenediimides (PDI) and their derivatives can be convenient starting materials for the modular synthesis of our dielectrophores. Synthesis of the cores with higher symmetry (e.g. porphyrins, triphenylenes) represents a significant challenge. Notably, working with the PDI, lateral or longitudinal extensions, as well as the substitution in the bay- and ortho-positions (see Figure 3 ) could be easily performed to optimize the polarizability. Meanwhile, manipulating with the imide function, we can modify the PDI into greater conjugated aryl-pyrimidine or aryl-imidazole derivatives, and at the same time, add the insulating subunits. This modularity of the rylenes makes them unique candidates, as compared to the other $\pi$-stackable cores, such as porphyrins and benzocoronenes.

In this article, we demonstrate fundamental principles of the polarizability tuning, using the scope of the perylene derivatives. Going through the main molecular elements, we determine their impact on both linear polarizability $(\alpha)$ and hyperpolarizability. In the approximation that we suggest here, we only consider first hyperpolarizability $(\beta)$ to have an opportunity to involve a significant number of molecules. Hence, our screening mainly focuses on the calculated values of $\alpha$ and $\beta$, instead of focusing on their individual components (ground state dipole moment for $\alpha$, the energy gap between the two states, the transition dipole moment between the two states, and the difference in dipole moment between the two states for $\beta$ ). Since the dielectrophores that we consider have a generally linear shape, their polarizabilities are mainly dominated by the longitudinal tensor components (along the $x$-axis). During the self-assembly, this molecular direction would be aligned with the electric field produced by the electrodes, and, therefore, we only report the longitudinal tensor components $\alpha_{x x}$ and $\beta_{x x x}$ with the induced dipole moment of the dielectrophore given by

$$
p_{x}=\alpha_{x x} E_{x}+\beta_{x x x} E_{x}^{2}
$$




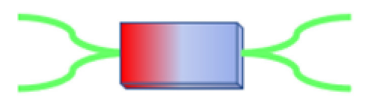

Rylene-based dielectrophore

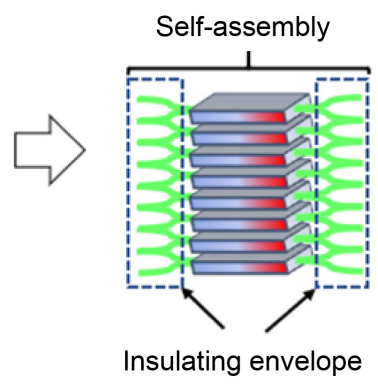

Figure 2. Formation of self-assemblies and nano-structures from rylene-based dielectrophores.

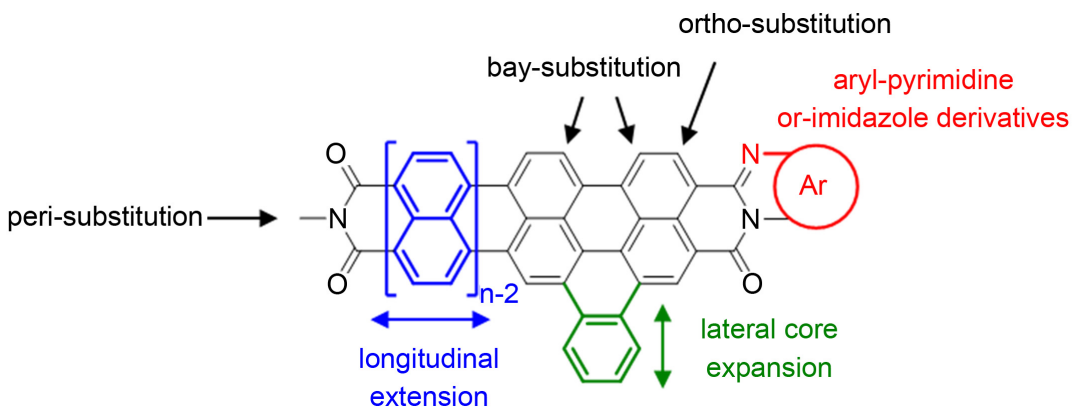

Figure 3. Possible directions of extension of the rylene-based dielectrophores.

where we keep only the first two terms in the power expansion. In addition, contributions of the resistive groups to the total polarizability is minimal, therefore, we use methyl substituents as resistive groups in our calculations.

\section{Results and Discussion}

We begin our study by the determination of the dependence of $\alpha$ and $\beta$ upon the electronic effects of the donor and acceptor groups, and upon longitudinal extension of the rylene aromatic core, since increased $\pi-\pi$ stacking has been seen for higher rylenes ( $n>2$; Figure 3$)$. At this step, we do not consider substitutions at peri-positions (Figure 3 ), since these positions are mainly used for addition of solubilizing chains. Substituents at peri-positions have a negligible influence on the absorption and emission of the core (at least within a single molecule), because the nodes of the HOMO and LUMO orbitals are located at the imide nitrogens [8].

In our study, we propose further change of the polarizability when adding donor/acceptor functional groups. These groups can be considered at various positions within the general structure of the rylene-based dielectrophore $\left(R^{1}-R^{8}\right.$; Figure 4). In our screening, we take advantage of the amino (as well as alkylamines) and nitro groups, since they are among the strongest donor and acceptor groups. In addition, amino group provides a convenient spot for the insertion of resistive groups (long alkyl chains) without interfering directly with the electronic properties of the conjugated core. Table 1 illustrates the results of our calculations. 


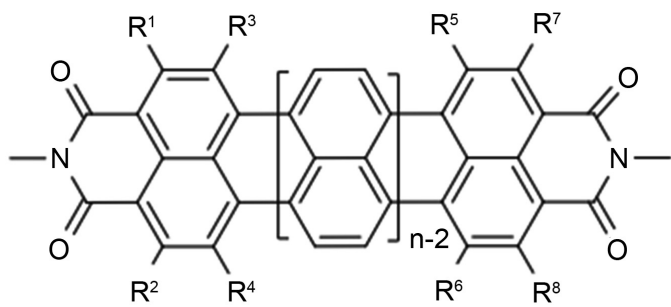

Figure 4. General structure of the PDI-based dielectrophores of a figure caption.

Table 1. Screening of PDI-based dielectrophores.

\begin{tabular}{cccccccccccc}
\hline Entry & $\mathbf{n}$ & $\mathbf{R}^{\mathbf{1}}$ & $\mathbf{R}^{2}$ & $\mathbf{R}^{\mathbf{3}}$ & $\mathbf{R}^{4}$ & $\mathbf{R}^{5}$ & $\mathbf{R}^{6}$ & $\mathbf{R}^{7}$ & $\mathbf{R}^{8}$ & $\boldsymbol{\alpha}_{\mathbf{x x}} / \mathbf{a} . \mathbf{u}$. & $\beta_{\mathbf{x x d}} / \mathbf{a} . \mathbf{u}$. \\
\hline $\mathbf{1}$ & 2 & $\mathrm{H}$ & $\mathrm{H}$ & $\mathrm{H}$ & $\mathrm{H}$ & $\mathrm{H}$ & $\mathrm{H}$ & $\mathrm{H}$ & $\mathrm{H}$ & 604 & 0.08 \\
$\mathbf{2}$ & 2 & $\mathrm{NH}_{2}$ & $\mathrm{NH}_{2}$ & $\mathrm{H}$ & $\mathrm{H}$ & $\mathrm{H}$ & $\mathrm{H}$ & $\mathrm{H}$ & $\mathrm{H}$ & 614 & 791 \\
$\mathbf{3}$ & 2 & $\mathrm{H}$ & $\mathrm{H}$ & $\mathrm{NH}_{2}$ & $\mathrm{NH}_{2}$ & $\mathrm{H}$ & $\mathrm{H}$ & $\mathrm{H}$ & $\mathrm{H}$ & 592 & 3714 \\
$\mathbf{4}$ & 2 & $\mathrm{H}$ & $\mathrm{H}$ & $\mathrm{H}$ & $\mathrm{NH}_{2}$ & $\mathrm{NH}_{2}$ & $\mathrm{H}$ & $\mathrm{H}$ & $\mathrm{H}$ & 626 & 0.1 \\
$\mathbf{5}$ & 2 & $\mathrm{NH}_{2}$ & $\mathrm{NH}_{2}$ & $\mathrm{H}$ & $\mathrm{H}$ & $\mathrm{H}$ & $\mathrm{H}$ & $\mathrm{NH}_{2}$ & $\mathrm{NH}_{2}$ & 578 & 0.47 \\
$\mathbf{6}$ & 2 & $\mathrm{H}$ & $\mathrm{H}$ & $\mathrm{H}$ & $\mathrm{NO}_{2}$ & $\mathrm{NH}_{2}$ & $\mathrm{H}$ & $\mathrm{H}$ & $\mathrm{H}$ & 610 & 656 \\
$\mathbf{7}$ & 2 & $\mathrm{NO}_{2}$ & $\mathrm{NO}_{2}$ & $\mathrm{H}$ & $\mathrm{H}$ & $\mathrm{H}$ & $\mathrm{H}$ & $\mathrm{NH}_{2}$ & $\mathrm{NH}_{2}$ & 620 & 9404 \\
$\mathbf{8}$ & 3 & $\mathrm{NO}_{2}$ & $\mathrm{NO}_{2}$ & $\mathrm{H}$ & $\mathrm{H}$ & $\mathrm{H}$ & $\mathrm{H}$ & $\mathrm{NH}_{2}$ & $\mathrm{NH}_{2}$ & 1130 & 34,067 \\
$\mathbf{9}$ & 4 & $\mathrm{NO}_{2}$ & $\mathrm{NO}_{2}$ & $\mathrm{H}$ & $\mathrm{H}$ & $\mathrm{H}$ & $\mathrm{H}$ & $\mathrm{NH}_{2}$ & $\mathrm{NH}_{2}$ & 1842 & 83,211 \\
$\mathbf{1 0}$ & 5 & $\mathrm{NO}_{2}$ & $\mathrm{NO}_{2}$ & $\mathrm{H}$ & $\mathrm{H}$ & $\mathrm{H}$ & $\mathrm{H}$ & $\mathrm{NH}_{2}$ & $\mathrm{NH}_{2}$ & 2757 & 175,140 \\
$\mathbf{1 1}$ & $\mathbf{6}$ & $\mathrm{NO}_{2}$ & $\mathrm{NO}_{2}$ & $\mathrm{H}$ & $\mathrm{H}$ & $\mathrm{H}$ & $\mathrm{H}$ & $\mathrm{NH}_{2}$ & $\mathrm{NH}_{2}$ & 3867 & 329,201 \\
$\mathbf{1 2}$ & 7 & $\mathrm{NO}_{2}$ & $\mathrm{NO}_{2}$ & $\mathrm{H}$ & $\mathrm{H}$ & $\mathrm{H}$ & $\mathrm{H}$ & $\mathrm{NH}_{2}$ & $\mathrm{NH}_{2}$ & 5160 & 569,212 \\
$\mathbf{1 3}$ & 8 & $\mathrm{NO}_{2}$ & $\mathrm{NO}_{2}$ & $\mathrm{H}$ & $\mathrm{H}$ & $\mathrm{H}$ & $\mathrm{H}$ & $\mathrm{NH}_{2}$ & $\mathrm{NH}_{2}$ & 6621 & 919,430 \\
\hline
\end{tabular}

The suggested molecules are analyzed with Gaussian09 software [9], their polarizabilities and hyperpolarizabilities are determined using the B3LYP method with 6-31G+ basic sets.

Initial screening of the perylene-based dielectrophores $(\mathrm{n}=2$, Table 1$)$ shows, that electronic properties and positions of the functional groups have minimal effects on linear polarizability (entries 1 - 6). Only a single order difference in $\alpha$ values was achieved within these first entries. On the other hand, entries 7 to 13 demonstrate that longitudinal extension greatly affects non-linear polarizability by distorting the electronic distribution. One should keep in mind that these three orders leap in the $\beta$ values (from entry 7 to entry 13) would not be reached without electron-donating and electron-withdrawing groups at opposite sides of the molecules $\left(R^{1}, R^{2}, R^{7}, R^{8}\right.$; Figure 4$)$. Generally, the first-order hyperpolarizability $(\beta)$ is expected to be higher, when the donor and acceptor groups are at the opposite sides of the conjugated system.

The discovered polarizability trend falls within well-established methodologies of push-pull chromophores design, developed for the nonlinear optical (NLO) properties [10]. The internal charge transfer (ICT) is responsible for the polarization of the chromophore, and the generation of the molecular dipole.

At the second step of our screening (Table 2), we compare the effects of 


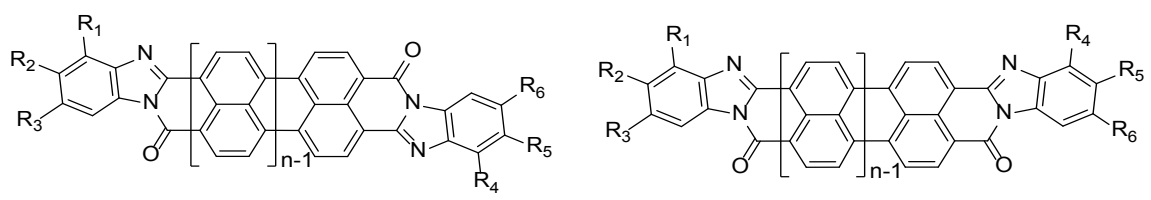

Figure 5. General structure of the PDI-benzimidazole-based dielectrophores.

Table 2. Screening of dielectrophores with PDI-benzimidazole cores.

\begin{tabular}{ccccccccccc}
\hline Entry & Conf. & $\mathbf{n}$ & $\mathbf{R}^{1}$ & $\mathbf{R}^{2}$ & $\mathbf{R}^{\mathbf{3}}$ & $\mathbf{R}^{4}$ & $\mathbf{R}^{\mathbf{5}}$ & $\mathbf{R}^{6}$ & $\boldsymbol{\alpha}_{\mathbf{x x}} / \mathbf{a} . \mathbf{u}$. & $\boldsymbol{\beta}_{\mathbf{x x d}} / \mathbf{a} . \mathbf{u}$. \\
\hline $\mathbf{1}$ & $\mathrm{ANTI}$ & 2 & $\mathrm{H}$ & $\mathrm{H}$ & $\mathrm{H}$ & $\mathrm{H}$ & $\mathrm{H}$ & $\mathrm{H}$ & 1348 & 0.165 \\
$\mathbf{2}$ & $\mathrm{ANTI}$ & 2 & $\mathrm{H}$ & $\mathrm{NO}_{2}$ & $\mathrm{H}$ & $\mathrm{H}$ & $\mathrm{NO}_{2}$ & $\mathrm{H}$ & 1537 & -862 \\
$\mathbf{3}$ & ANTI & 2 & $\mathrm{H}$ & $\mathrm{NMe}_{2}$ & $\mathrm{NO}_{2}$ & $\mathrm{H}$ & $\mathrm{NMe}_{2}$ & $\mathrm{NO}_{2}$ & 2201 & 15.2 \\
$\mathbf{4}$ & ANTI & 2 & $\mathrm{H}$ & $\mathrm{NH}_{2}$ & $\mathrm{H}$ & $\mathrm{H}$ & $\mathrm{NO}_{2}$ & $\mathrm{H}$ & 1252 & 21,107 \\
$\mathbf{5}$ & ANTI & 2 & $\mathrm{H}$ & $\mathrm{NH}_{2}$ & $\mathrm{NH}_{2}$ & $\mathrm{H}$ & $\mathrm{NO}_{2}$ & $\mathrm{NO}_{2}$ & 1546 & 119,079 \\
$\mathbf{6}$ & ANTI & 2 & $\mathrm{H}$ & $\mathrm{NO}_{2}$ & $\mathrm{NH}_{2}$ & $\mathrm{H}$ & $\mathrm{NH}_{2}$ & $\mathrm{NO}_{2}$ & 1431 & 35,199 \\
$\mathbf{7}$ & ANTI & 2 & $\mathrm{NH}_{2}$ & $\mathrm{H}$ & $\mathrm{DB}$ & $\mathrm{NO}_{2}$ & $\mathrm{H}$ & $\mathrm{DB}$ & 1809 & 76,729 \\
$\mathbf{8}$ & SYN & 2 & $\mathrm{NH}_{2}$ & $\mathrm{H}$ & $\mathrm{DB}$ & $\mathrm{NO}_{2}$ & $\mathrm{H}$ & $\mathrm{DB}$ & 1813 & 83,998 \\
$\mathbf{9}$ & ANTI & 3 & $\mathrm{NH}_{2}$ & $\mathrm{H}$ & $\mathrm{DB}$ & $\mathrm{NO}_{2}$ & $\mathrm{H}$ & $\mathrm{DB}$ & 2557 & 136,920 \\
$\mathbf{1 0}$ & SYN & 3 & $\mathrm{NH}_{2}$ & $\mathrm{H}$ & $\mathrm{DB}$ & $\mathrm{NO}_{2}$ & $\mathrm{H}$ & $\mathrm{DB}$ & 2559 & 142,141 \\
$\mathbf{1 1}$ & ANTI & 4 & $\mathrm{NH}_{2}$ & $\mathrm{H}$ & $\mathrm{DB}$ & $\mathrm{NO}_{2}$ & $\mathrm{H}$ & $\mathrm{DB}$ & 3477 & 215,093 \\
$\mathbf{1 2}$ & SYN & 4 & $\mathrm{NH}_{2}$ & $\mathrm{H}$ & $\mathrm{DB}$ & $\mathrm{NO}_{2}$ & $\mathrm{H}$ & $\mathrm{DB}$ & 3478 & 218,934 \\
$\mathbf{1 3}$ & ANTI & 2 & $\mathrm{NEt}_{2}$ & $\mathrm{H}$ & $\mathrm{DB}$ & $\mathrm{NO}_{2}$ & $\mathrm{H}$ & $\mathrm{DB}$ & 1910 & 111,414 \\
\hline
\end{tabular}

DB-3,5-dimethoxyphenyl.

common donor and acceptor groups on linear and nonlinear polarizability of less synthetically challenging PDI-benzimidazole dielectrophores shown in Figure 5. At this step, we compare SYN and ANTI PDI-based dielectrophore structures (Figure 5), since these structures are possible synthetically made regioisomers.

At this step, $\alpha$ values again stayed within the same order of magnitude (Table 2 ). The notable leap in $\beta$-values can be observed in the entry 5 , when we double the numbers of donor and acceptor groups at opposite sides of the molecule (donor group as $\mathrm{R}^{2}, \mathrm{R}^{3}$ and acceptor group as $\mathrm{R}^{5}, \mathrm{R}^{6}$; Figure 5 ). In the next entry (entry 6), we can see that $\beta$-value of our rylene-based structure significantly drops when having both donor and acceptor groups at each side (donor group as $R^{3}, R^{5}$ and acceptor group as $R^{2}, R^{6}$; Figure 5). This way we confirm, that it is crucial for the molecule with high non-linear polarizability to have all donor groups at one side and acceptor groups on the opposite side (as in the entry 5). Later, we found that having only a single donor and acceptor groups correspondingly and positions of $\mathrm{R}^{1}$ and $\mathrm{R}^{4}$ substituents also provides relatively high values of non-linear polarizability (Entries 7 - 13). This inspiring result indicates perfect spots for the installation of donor and acceptor groups in the desired synthetically accessible dielectrophores. In addition, similarly to the first part of our screening, longitudinal extension clearly demonstrates growing trend $(n=2-4$, 


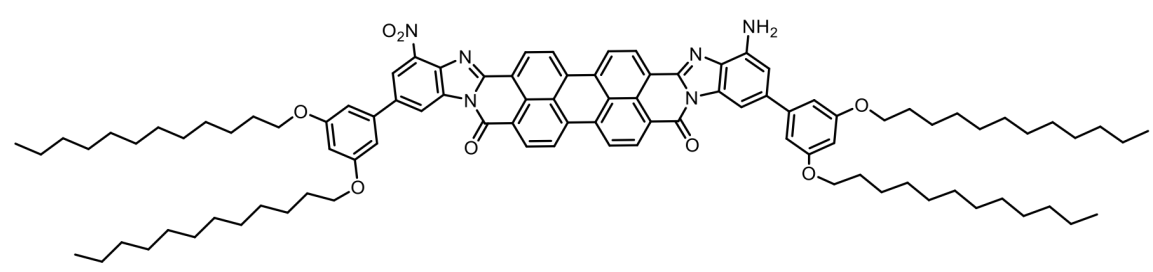

Figure 6. Suggested dielectrophore structure.

entries 7 - 12).

Our examples possess simple donor and acceptor groups, as well as relatively short conjugated systems. Replacing the donor and acceptor groups with more complex subunits, together with the extended longitudinal axis (rylenes with $n>$ 4) can provide even higher polarizable molecules. However, we must seriously take the synthetic aspect into our consideration, since it is an inevitable element of the molecular design. The synthesis of more complex molecules would be quite challenging. In addition, we should not forget about much higher resistivity requirements of such systems.

In our ideal perylene-based dielectrophore, resistive groups should be added symmetrically at both ends of the molecules, close to the terminal donor and acceptor groups. Adding two long alkyl chains at both ends, via a phenyl linker, allows for maintaining the relative symmetry of the molecule to favor columnar arrangements (Figure 2), other than alternative micellar structures [11].

Considering the calculation results, as well as the synthetic flexibility, price, and the resistivity requirements, we worked out the structure of the proposedly efficient dielectrophore molecule, as shown in Figure 6. This suggested dielectrophore follows the principles discussed above and contains both donor and acceptor groups at corresponding positions of $\mathrm{R}^{1}$ and $\mathrm{R}^{4}$ substituents, as well as resistive alkane chains on the periphery of the molecule.

\section{Conclusions}

We have discussed the feasibility of heavy-duty capacitors based on dielectrophores. Using quantum chemistry calculations, based on the series of perylene-based molecules, we demonstrated that introduction of donor and acceptor groups at the certain positions increases hyperpolarizability. This result is expected based on literature and data produced in non-linear optics studies. Alternatively, a rise of polarizability can be achieved by expansion of the aromatic core, i.e. by increasing the number of electrons available for displacement along the molecular structure.

In addition to the calculations, we suggested a structure for the future dielectrophore. It includes the highly polarizable aromatic core and highly resistive aliphatic tails. $\pi-\pi$ interaction of conjugated cores would lead to the column-like molecular self-assembly. Proposed molecule is expected to have large linear and non-linear polarizabilities, high molecular density, and low leakage current, which makes it applicable for capacitive energy storage industry. 


\section{References}

[1] Larcher, D. and Tarascon, J.M. (2014) Towards Greener and More Sustainable Batteries for Electrical Energy Storage. Nature Chemistry, 7, 19-29. https://doi.org/10.1038/nchem.2085

[2] Dummer, G.W.A. (1997) Electronic Inventions and Discoveries. 3rd Edition, Institute of Physics Publishing, Bristol, UK, 74.

[3] Lazarev, P.I., Furuta, P.T., Sharp, B.K., Li, Y. and Kelly-Morgan, I.S.G. (2017) Electro-Polarizable Compound and Capacitor. US Patent No.20170287638.

[4] Langhals, H. (1988) Dyes with High Dielectric Constants. Chemical Physics Letters, 150, 321-324. https://doi.org/10.1016/0009-2614(88)80050-2

[5] Zhan, X., Facchetti, A., Barlow, S., Marks, T.J., Ratner, M.A., Wasielewski, M.R. and Marder, S.R. (2011) Rylene and Related Diimides for Organic Electronics. Advanced Materials, 23, 268-284. https://doi.org/10.1002/adma.201001402

[6] Chen, Z., Lohr, A., Saha-Möller, C.R. and Würthner, F. (2009) Self-Assembled $\pi$-Stacks of Functional Dyes in Solution: Structural and Thermodynamic Features. Chemical Society Reviews, 38, 564-584. https://doi.org/10.1039/B809359H

[7] Shackelford, J.F. and Alexander, W. (2001) CRC Materials Science and Engineering Handbook. 3rd Edition, CRC Press, Boca Raton, 1767.

[8] Nagao, Y. (1997) Synthesis and Properties of Perylene Pigments. Progress in Organic Coatings, 31, 43-49. https://doi.org/10.1016/S0300-9440(97)00017-9

[9] Frisch, M., et al. (2009) Gaussian 09. Revision E.01, Gaussian Inc., Wallingford CT.

[10] Nalwa, H.S., Watanabe, T. and Miyata, S. (1997) Nonlinear Optics of Organic Molecules and Polymers. CRC Press, Boca Raton, 89.

[11] Görl, D., Zhang, X. and Würthner, F. (2012) Molecular Assemblies of Perylene Bisimide Dyes in Water. Angewandte Chemie International Edition, 51, 6328-6348. https://doi.org/10.1002/anie.201108690 